\title{
An imitation model of the financial-economic mechanism of taking strategic decisions at the enterprise
}

\author{
Iryna Trunina ${ }^{1, *}$, Iryna $\mathrm{Kushal}^{2}$, and Denys Zagirniak ${ }^{3}$ \\ ${ }^{1}$ Doctor of Economics, professor, Kremenchuk Mykhailo Ostrohradskyi National University, Ukraine \\ ${ }^{2} \mathrm{PhD}$ candidate, associate professor, Volodymyr Dahl East Ukrainian National University, Ukraine \\ ${ }^{3} \mathrm{PhD}$ candidate, associate professor, Kremenchuk Mykhailo Ostrohradskyi National University, \\ Ukraine
}

\begin{abstract}
The crisis conditions of the enterprise functioning restrain the possibilities for the innovation activity and lay down higher requirements to the determination of the tasks of the financial strategy of development. To enhance the adaptive possibilities the authors propose to use an imitation-class mathematical model, indicate the basic stages of its creation, determine the structure: a control system; a functional system consisting of functional financial and economic blocks, an information system including a database. We distinguished the basic indices for the analysis of the ability of the enterprise to take strategic decisions of both financial and economic components of the mechanism of their realization. The practical realization of the proposed imitation model of the financialeconomic mechanism of taking strategic decisions based on the calculation of the integral index provides the required information basis for the grounded strategic decision and further development of the enterprise.
\end{abstract}

Key words: model, mechanism, management, decision, enterprise

\section{Introduction}

The transformation condition of the economy development requires from the top managers not only certain skills and knowledge of the management practice, but also taking into account all the factors of influence on the enterprise activity and, first of all, taking into account the risk factor inherent in the nature of strategic decisions. One can solve this problem by creation of models, which will make it possible not only to facilitate the stages of the routine analysis but also to automate them. All this enables the manager to have additional time for the creative approach to taking strategic decisions, which will improve their quality in the future and enhance the level of the management work.

In practice the situation when the enterprise takes strategic decisions under the conditions of risk occurs most often as risk is an inseparable part of economic life. One can choose a decision reducing the risk but it is impossible to avoid it. Most often an enterprise does not try to avoid risk when taking strategic decisions but it tries to minimize it using the instruments of insurance and financial market. At the stage of the development of a

* Corresponding author: deniszagirniak@gmail.com 
managerial decision it is expedient to use modeling methods to reduce the cost of further insurance against financial losses after their realization.

Well-known economists of the world have performed fundamental research in this field. So, J.K. Lafta made an essential contribution into the research of the category of "mechanism" concerning taking strategic decisions. He considered it an "apparatus" or a "device" [1]. W. Cherchmen, R. Ackoff, L. Arnof stated that the presence of a mechanism of taking strategic decisions is the key to success, the efficiency in realization and modeling their basic parameters [2]. A. Kulman had the same opinion [3].

Modeling does not cancel the use of experience and intuition of the person who takes the decision; on the contrary, their significance grows. Modeling is a certain formalized type of experience and makes it possible to control the intuitive representations of the leaders of the enterprise. The person who takes a decision can supplement the model with the required qualitative analysis taking into account his/her own experience. Thus, the model supports the manager in the process of making strategic decisions but in no way replaces him/her [4].

\section{Data and Methods}

Top managers should pay special attention to the creation of the models of taking strategic decisions because: the solutions are of a non-changeable character; the termination of the realization of the initiated long-term projects or even essential changes in them are sometimes impossible due to economic criteria; the success of strategic decisions, first of all, exclusively depends on top managers; the effect of the taken strategic decisions is measured by thousands and millions monetary units. Under such conditions the support of strategic decisions by means of modeling is necessary and topical, certifies the expediency of the use of this method during taking decisions and justifies material and labor costs of its use.

The use of modeling in the process of taking decisions makes it possible to support such advanced managerial principles as system, multivariate analysis, taking into account the uncertainty of the activity conditions, financial-economic risk, the complexity of taking into account the financial, economic social and other consequences of decision realization.

\section{Results}

\subsection{The purpose of the research}

One of the most important conditions of taking high-quality strategic decisions in the field of finance consists in the availability of the financial-economic mechanism of the process of their taking and the improvement of this mechanism. So, the creation of a model of financial-economic mechanism of taking strategic decisions is the purpose of the research. It will promote the decisions efficiency, the increase of financial profit, the simplification and automation of the decision-taking process, the improvement of their organizational and informational support. Besides it is the key factor of management success.

The use of modeling in the process of taking strategic decisions does not reduce the significance and the intuition of the manager; on the contrary, when used correctly, it promotes the development of the initiative of the employees who are to put these decisions into practice. 


\subsection{The analysis of the basic parameters of the imitation model of the financial-economic mechanism of taking strategic decisions at the enterprise}

Having generalized the information from economic literature and having performed substantial research, the authors can propose the following definition of a "model of a financial-economic mechanism of taking strategic decisions". It is a dynamic object reflecting the interdependences and relations of its components and serving to identify the alternatives of financial and economic development under the influence of the external and internal factors of the enterprise activity environment.

Under the conditions of transformation economy the need for efficient scientifically substantiated economic forecasts does not decrease, on the contrary, it essentially increases. That is why it is necessary to look for the ways for the correlation of the content and organization of the development of financial-economic forecasting with the changes taking place in all the fields of activity. A complex program-oriented forecast of the financial and economic development of the enterprise under the conditions of the transformation economy is necessary. It causes the use of mathematical models whose creation requires taking into account certain elements. They include a problem situation; the term of taking a strategic decision; the necessary resources; a system of factors subject to management; unmanageable factors; the state of the environment (by the unmanageable factors); the system of restrictions (resource, time, legal, social etc.); a system of manageable factors relations; a system of unmanageable factors relations; the result of the actions; a system of the criteria for the determination of the actions result correspondence to the posed purpose; a system of the usefulness functions for the estimation of the result by the criteria system; a system of functions for the estimation of the expected effect of the actions realization; a complex estimation of the alternatives; an optimal strategic decision.

In the course of the research, it was found that the quality of a strategic decision would increase if senior executives would take into account the manifestation of the laws of the organization, namely the law of synergy. In making strategic decisions, synergy means the strategic advantages of the enterprise, in which synergies between the components of the financial and economic decision-making mechanism take the form of strategic business development. Synergetic relationships between the components of the financial and economic mechanism for making strategic decisions play the major role, since they are the building forces of the constituent parts, and vice versa, their weakness leads to the breakdown of communications and its disintegration as a holistic creation. Therefore, the practical and organizational problem is the choice of methods, approaches and system of indicators for assessing synergy effects when making strategic decisions, the solution of which requires the introduction of a certain evaluation mechanism, which will allow to quantify the results of the manifestation of synergy and determine the components of the financial and economic mechanism of adoption solutions that need to be strengthened to get synergistic benefits in the future. One of the main conditions for the emergence of synergistic effects when making strategic decisions is the presence of an effective financial and economic mechanism in the enterprise.

The concrete forms of manifestation of synergy in enterprises when making strategic decisions are: team synergy and improvement of corporate culture; cost reduction; managerial competence (managerial synergy); trade synergy; operational synergy; investment synergy; accelerating the movement of information; cash flow growth (financial synergy), etc.

By the positive values of all the parameters of the financial and economic component, there is certainly a synergistic effect and the question of its quantification is raised. Justification by means of an appropriate system of calculations of the most economically advantageous strategic alternative solution based on multicriteria optimization is one of the possible ways of practical realization of the synergetic methodology, namely: the sources of 
the synergistic effect, the classification of synergy, the consideration of the principles and principles of synergetics, the determination of the type of the system under study and nature of the manifestation of synergy depending on it.

Open systems are characterized by the presence of more powerful sources of development, metabolism and energy with the environment. All this is also relevant for economic systems and the enterprise is the most open system, which is inherent in measures of strategic management. For a company as an open system in a market environment, the manifestation of synergy will be fundamentally different, depending on the level of competition.

At high intensity of competition, the main losses of synergy of the enterprise are changing the direction of development, that is, enterprises are forced to lose additional synergy reserves for structural or assortment policy, etc. But intense competition forces most of companies to start balanced strategic and tactical measures. As the intensity of competition decreases, there is a general decrease in the "energy tone" of the enterprise. That is, because of the low intensity of enterprise competition, the lower value of final synergy. At zero intensity of competition, synergy effects are zero. This situation is dangerous in nature.

It should be emphasized that the synergy effect is a somewhat complex phenomenon that needs to be planned and used. The management of an enterprise should create the necessary conditions for the realization of the potential synergy effect. Otherwise, there may be a negative synergy effect.

In the practice of strategic management, the calculation of a positive synergistic effect ensures the verification of strategic decisions at the development stage for the purpose of meeting the strategic goals of the objective conditions of functioning in the market, using the integral indicator, since the financial and economic components are not homogeneous. As a result of the calculation of the integral indicator, one can judge the effectiveness of the whole team, and above all, the effectiveness of senior management, those who take strategic decisions at the enterprise.

Calculation data of integral indicators of estimation of economic and financial components of making strategic decisions will be the starting point for building an effective model of the mechanism of making strategic decisions of enterprises and an indicator of determining the success of their activity at the appropriate stage of development.

The basic stages of the creation of the model of financial-economic mechanism of taking strategic decisions at an enterprise include: the determination of financial purposes; the determination of the manageable components and the structure of the model; the choice of the model type in accordance with the financial purpose; the estimation, testing and modification of the manageable components of the model; the verification of the model adequacy to the conditions of financial-economic development; economic interpretation of the obtained results.

The formation of adequate requirements to the creation of the model of financialeconomic mechanism of taking strategic decisions rests on the difference between the strategic decisions concerning the field of activity (the object of management on the whole) and the enterprise. So, for their realization in practice the managers must know if the acting financial-economic mechanism meets the requirements of the decision (capital, manufacturing capacity, cost policy, property status, etc.), if it is possible to approve of the decision under the existing activity conditions.

The solution to this problem consists in the use of an imitation-class economicmathematical model with the following advantages: it allows the description of the process simulated with higher adequacy than others; it is characterized by certain flexibility of the structure, algorithms and parameters of the system; it provides the possibility for the application of computer hardware, which essentially reduces the time and cost of the task 
solution.

The proposed structure of the imitation model of the financial-economic mechanism of taking strategic decisions consists of three parts: a control system; a functional system including three blocks; an information system including a database.

In its turn, the control system contains a modeling control block; a dialog block, a block for processing the modeling results; an event calendar.

Due to the proposed imitation model of the financial-economic mechanism of taking strategic decisions at the enterprise it is possible not only to calculate its basic parameters but also to estimate its correspondence to the requirements of the managerial decision, i.e. to determine the degree and the ability of the enterprise to take a certain decision.

In the authors' opinion, the readiness of the enterprise to take strategic decisions is characterized by a financial component (the efficiency of the use of the capital, the efficiency of the activity, the structure of expenditure, the production program, the taxation policy) and an economic component (the characteristic of the managerial structure, industrial engineering, management organization), which reflects on the proposed imitation model of financial-economic mechanism of taking strategic decisions by the composition of its functional system (the financial and economic block).

This analysis is performed in the imitation model of the financial-economic mechanism of taking strategic decisions at the enterprise in the functional system, namely, in the block of calculation of the financial indices concerning taking strategic decisions and in the block of calculation of the economic indices concerning taking strategic decisions. The indices are to be calculated in dynamics before and after taking strategic decisions to determine the lines of improvement.

According to the presented structural-logical scheme of the analysis of the ability of the enterprise to take strategic decisions and the determination of the indices of the estimation of the financial-economic mechanism of taking strategic decisions included into the functional system of the imitation model, this process is to be performed in the following order: the formation of the system of indices that by their nature reflect the features and regularities of each component of the enterprise ability (financial, economic) to take strategic decisions; the calculation of the indices values, the determination of their significance and reference values; the calculation of the integral index of the ability of the enterprise to financial-economic development and taking strategic decisions; making conclusions by the results of the analysis.

The analysis of the theoretical developments and the diagnostics of the financialeconomic mechanism of taking strategic decisions at the enterprise made it possible to identify the following indices for the analysis of the ability of the enterprise to take strategic decisions:

I. The indices of the analysis of the financial component of the ability of the enterprise to take strategic decisions: a) the efficiency of the use of the capital: the coefficient of autonomy, financial leverage, long-term financial independence, relation of the long- and short-term liabilities, the period of capital turnover, of equity turnover, financial dependence, the concentration of loan capital, financial stability; b) the efficiency of the activity: of the own working capital turnover, provision of current assets by own funds, current liquidity, that characterizes the component of short-term liabilities in the capital of the enterprise, profitability of sales on net profit, sales for gross income; c) the production program: the dynamics of the change of the proceeds from sales, net profit; d) the cost structure: the structural dynamics of the cost by the elements, constant and variable cost; e) the property status: the share of current assets in the working capital, the share of fixed means in assets, the coefficient of the fixed assets wear, renewal of the fixed assets, mobility of the assets; f) the taxation policy: the index of the general taxation level, the coefficient of taxation efficiency, tax-capacity of the sold product, taxation of the enterprise 
income, taxation of the cost, taxation of profits, preferential taxation.

II. The indices of the analysis of the economic component of the enterprise ability to take strategic decisions: a) industrial engineering: the coefficient of the automation of the production process, the coefficient of uninterrupted process, the coefficient of renewal; $b$ ) the organization of management: the coefficient of position regulation, the coefficient of the completeness of the coverage of management functions, the coefficient of the economy of the management system, the coefficient of the reliability of the operation of the management personnel; c) the structure of management: the coefficient of the structure flexibility, the coefficient of the structure specialization, the coefficient of the structural subdivisions regulation, the coefficient of the organizational structure orientation to the market.

The presented indices vary within the interval from 0 to 1 and are stimulators as to their nature. One should determine the total amount of the financial and economic components of the readiness to taking strategic decisions based on the integral index by formula (1):

$$
\operatorname{Ig} \sum_{i=1}^{n} V_{i j} \frac{X_{i j}}{X e_{i j}},
$$

where $V_{i j}$ - the significance of the $i$-th index of the $j$-th component; $X_{i j}$ - the factual value of the $i$-th index of the $j$-th component; $X e_{i j}$ - the reference value of the $i$-th index of the $j$-th component.

The higher the value of the integral index is the higher the level of the ability to take strategic decisions is.

\subsection{The comparative analysis of the results of modeling the financial- economic mechanism of taking strategic decisions}

The practical realization of the proposed imitation model of the financial-economic mechanism of taking strategic decisions based on the calculation of the integral index of the financial and economic components will provide the necessary database for the substantiation of the managerial decision and further financial-economic development of the enterprise.

We will represent the financial-economic mechanism of taking strategic decisions at the enterprise, which corresponds to the chosen financial strategy of development, by means of a production function enabling the estimation of the resource return, working out a variant of the development plan and the optimization of enterprise functioning and it will be of the form (2):

$$
Y=f\left(R_{1}, R_{2}, \ldots, R_{i}, \ldots R_{n}\right),
$$

where $Y$ - the desired parameters of the financial-economic mechanism of taking strategic decisions at the enterprise in accordance with the chosen financial strategy of development; $R$ - the factor indices of the $i$-th resources included into the components (financial and economic) of the mechanism of taking managerial decisions; $n$ - the number of the factor indices of financial-economic mechanism of taking strategic decisions.

The following groups of assumptions determine the function of the corresponding financial-economic mechanism of taking strategic decisions: mathematical assumptions the function of the readiness of the financial-economic mechanism of taking managerial decision is continuous and twice differentiated; economic assumptions: [5]:

1) should at least one resource be absent, it is impossible to take strategic decisions (3) 


$$
\begin{aligned}
& Y\left(0, R_{1}, \ldots, R_{i}, \ldots R_{n}\right)=\ldots= \\
& =Y=f\left(R_{1}, R_{2}, \ldots, 0, \ldots R_{n}\right)=\ldots= \\
& =f\left(R_{1}, R_{2}, \ldots, R_{i}, \ldots 0\right)=0
\end{aligned}
$$

2) the growth of factor indices results in the increase of the efficiency (ability) of the financial-economic mechanism of taking strategic decisions (4):

$$
\frac{\partial Y}{\partial R_{i}}>0, \text { at } R_{i}>, i=1,2, \ldots n
$$

3) the cost increase does not result in the decrease of the efficiency of the financialeconomic mechanism of taking strategic decisions (5):

$$
\frac{\partial^{2} Y}{\partial R_{i}^{2}}<0, i=1,2, \ldots n
$$

Based on the above said, the character of the factor indices influence on the efficiency of the financial-economic mechanism of taking strategic decisions is variable. So, it is necessary to determine their phase coordinates in the imitation model and represent them as $r_{1}, r_{2}, \ldots r_{n}$, and the ability to take a particular strategic decision - as functions $y_{1}(t), y_{2}(t)$, $\ldots, y_{n}(t)$. We will take the initial moment of functioning of the financial-economic mechanism of taking strategic decisions in time as $t_{0}$. Then we can consider that at the enterprise there is a financial-economic mechanism of taking strategic decisions, corresponding to the financial strategy of development, if for every $t>t_{0}$ it is possible to calculate its position exactly and unambiguously, i.e. to find functions $r_{1}(t), r_{2}(t), \ldots, r_{n}(t)$, characterizing the change of the phase coordinates in time. The dynamics of values $r$ and $y=\left(y_{1}, y_{2}, \ldots, y_{n}\right)$ will represent the process of realization of the strategic decision in time by the corresponding financial-economic mechanism. Based on the above said, we provide the process of realization of the financial strategy of enterprise development with the indices of readiness to taking strategic decisions such as profitability of sales, accumulation, labor productivity, etc.

The main task of the financial-economic development of the enterprise based on the above listed assumptions is formed in the following way: at the initial moment of time $t_{0}$ the enterprise is in the phase condition $y_{0}$; it is necessary to choose such financial-economic mechanism of taking strategic decisions $y(t)$, that in time $t_{1}$ will take the enterprise in the phase condition $y_{1}$. Values $t_{1}$ and $y_{1}$ are set by the chosen financial strategy of development and characterize the ability of the enterprise to take a particular strategic decision. If the financial strategy of the enterprise development implies the provision of the financialeconomic mechanism of taking strategic decisions with the determined factor indices of the $i$-th resources (6):

$$
y(t)=\left(r_{1}(t)\right),\left(r_{2}(t)\right), \ldots,\left(r_{n}(t)\right)=\text { const } .
$$

Negative influence of the external or internal environment may put the financialeconomic mechanism of taking strategic decisions out of the stable condition, which makes the determination of the future state $\left(y_{1}\right)$ impossible under such conditions [6]. For efficient realization of the financial-economic mechanism of taking strategic decisions at the enterprise, we should have a set of its determined functions $y(t)$, which allow returning it into the working condition $y_{0}$ from any point $y_{1}$. Under such conditions we can represent the mathematical model of the financial-economic mechanism of taking strategic decisions at the enterprise by the following system of differential equations (7): 


$$
\begin{aligned}
& y_{1}=f_{1}\left(r_{1}, \ldots r_{n}, y_{1}(t), \ldots y_{n}(t)\right) \\
& y_{2}=f_{2}\left(r_{1}, \ldots r_{n}, y_{1}(t), \ldots y_{n}(t)\right) \\
& \ldots \ldots \ldots \ldots \ldots \ldots \ldots \ldots \ldots \ldots \ldots \\
& y_{n}=f_{n}\left(r_{1}, \ldots r_{n}, y_{1}(t), \ldots y_{n}(t)\right)
\end{aligned}
$$

where $f(r, y)$ - functions of the ability of the financial-economic mechanism to take strategic decisions.

This system with known $t>t_{0}, y_{0}$ and the parameters of the financial and economic components of the mechanism of taking strategic decisions allows the unambiguous determination of the scheme of financial development of the enterprise.

In accordance with the proposed simulation model, we represent by means of the system of differential equations the ability of the financial and economic mechanism to make strategic decisions for the enterprise. The choice of indicators included in it was carried out using the expert estimation method. Experts were specialists in the number of 10 people working in the economic posts of the higher saber research enterprises. Practitioners have determined by the ball system from 1 to 10 the main factors influencing the area of research enterprises and the main indicators by which these factors can be estimated.

The main factors of the financial component of the experts were: efficiency of capital use, efficiency of activities, production program, cost structure, property status, tax policy. Accordingly, the indicators selected by experts were the following: the coefficient of autonomy, current liquidity, return on capital, the share of variable costs, mobility of assets, tax capacity of sales. The main economic factors according to experts: organization of production, management organization, organizational structure and indicators, by means of which they can be estimated - accumulation coefficient, profitability of sales, expenses per 1 monetary unit of revenues.

These indicators were calculated according to the financial statements of 5 large enterprises of one type of activity (industry) and one region in dynamics for 6 years and the results are presented in digital terms. For a comprehensive presentation of the enterprise ability to take strategic decisions it is reasonable to create a model according to the normative and average values of indices of the activity types (8):

*the factual value for

the enterprise

*the normative value $Y_{n}=f_{n}(0.70 ; 2.00 ; 0.15 ; 0.67 ; 1.00 ; 0.18 ; 0.30 ; 0.50 ; 0.09)$

* the value, average

for the activity type

$$
\begin{aligned}
& Y_{f}=f_{f}(0.58 ; 1.82 ; 0.15 ; 1.04 ; 2.63 ; 0.20 ; 0.44 ; 0.29 ; 11.57) \\
& Y_{n}=f_{n}(0.70 ; 2.00 ; 0.15 ; 0.67 ; 1.00 ; 0.18 ; 0.30 ; 0.50 ; 0.09) \\
& Y_{s}=f_{s}(0.14 ; 0.50 ; 0.08 ; 0.67 ; 4.45 ; 0.18 ; 2.31 ; 0.08 ; 0.09)
\end{aligned}
$$

If the selected indicators were not normative, the authors were guided by the average type of activity (industry).

\subsection{The problems and prospects of modeling the financial-economic mechanism of taking strategic decisions}

For clarity we present the obtained results of the imitation modeling of the financialeconomic mechanism of taking strategic decisions at the enterprise in a $3 \mathrm{D}$ space, with which purpose we grouped the indices according to three features: those that characterize the sources of financing (the coefficient of autonomy, current liquidity and return on equity) and the assets control (assets mobility, the tax capacity of the sold product, the 
profitability of sales), and those that present the cost policy (the share of variable costs, the coefficient of accumulation, managerial costs per 1 monetary unit of profit. Applying the extrapolation method to each of the indices groups, we find the coordinates for the enterprises, for the activity type and the normative value of the indices (if there was no determined normative for the index, an average value in the type of activity was used). We plot the first group of indices on axis $x$ in the 3D space, the second and the third group respectively on axes $y$ and $z$ (Fig. 1) [5].

The obtained graphic model according to calculations formula 8 makes it possible to determine the line of change of the parameters of the financial-economic mechanism of taking strategic decisions according to the chosen financial strategy of the development and realization of the particular managerial decision in its scope. The graphic model is constructed according to the calculations of formula 8 and reflects the functions of actual, medium-sized and regulatory capabilities. With its help, we can instantly see what indicators need to be changed in our mechanism to achieve the goals of both financial and economic goals. Ideally, these three pieces should be as close as possible to each other.

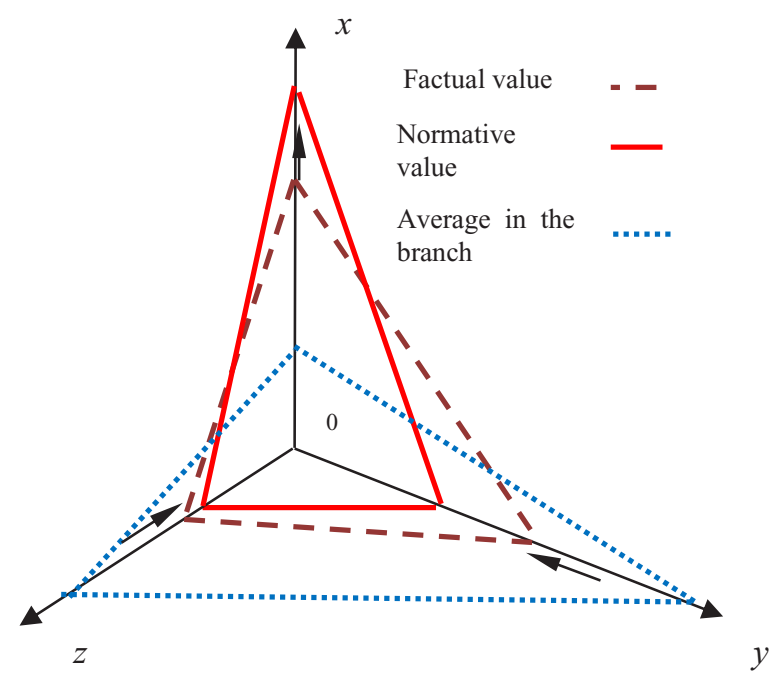

Fig. 1. A graphic model of the financial-economic mechanism of taking strategic decisions at the enterprise Source: [5].

We would like to emphasize the fact that the parameters of the financial-economic mechanism of taking strategic decisions cannot take absolutely arbitrary values and are subject to various restrictions: by the amount of the required capital, technological requirements, the personnel potential, etc. [6].

\section{Discussion and Conclusion}

Thus, the main result of our research includes: the interpretation of the "model of the financial-economic mechanism of taking strategic decisions" and creation of an imitation model, providing the enterprise with the properties of competitive advantage and market flexibility. The introduction of the imitation model of the financial-economic mechanism of taking strategic decisions at the enterprise will make it possible not only to calculate its basic parameters but also to estimate its correspondence to the requirements of the strategic 
decision and to determine the degree of the enterprise ability to realize them within the scope of the financial strategy of development.

\section{References}

1. I. Trunina, Development of entrepreneurship entity competitive strategy using competence-based approach. Actual problems of economics, 11(173), 206-213, (2015)

2. O. Sushchenko, I. Trunina, D. Zagirniak, Determination of electrical engineering business entity's core fields of competence as sources of its competitive advantages. Proceedings of the 2017 IEEE International Conference on Modern Electrical and Energy System (MEES), 344-347, (2017)

3. A. Kulman, Economic mechanisms. Moscow: Publishing Group "Progress", (1993)

4. R. Buhner, Personal management. Landsberg: Verlag Moderne Industrie, (1997)

5. T. Kalinescu, O. Antipov and I. Kushal, Strategy of social development: mechanism of decision-making process, 360, (2016)

6. W. Cherchmen, R. Ackoff, L. Arnof, Introduction to the study of operations. Moscow, 488, (1968) 